\title{
Congenital Cholesteatoma: Analysis of Risk Factors for the Postoperative Recurrence
}

\author{
Yun Seok Oh, Jeong Marn Kim, Hahn Jin Jung, See Ok Shin, and Young-Seok Choi \\ Department of Otorhinolaryngology-Head and Neck Surgery, Chungbuk National University Hospital, Chungbuk National University \\ College of Medicine, Cheongju, Korea
}

\section{선천성 진주종 수술 후 재발 위험인자에 대한 고찰}

\author{
오윤석 · 김정만 · 정한진 · 신시옥 · 최영석 \\ 충북대학교 의과대학 충북대학교병원 이비인후과학교실
}

\author{
Received April 11, 2017 \\ Revised July 4, 2017 \\ Accepted July 7, 2017 \\ Address for correspondence \\ Young-Seok Choi, MD, PhD \\ Department of Otorhinolaryngology- \\ Head and Neck Surgery, \\ Chungbuk National University \\ Hospital, Chungbuk National \\ University College of Medicine, \\ 776 1sunhwan-ro, Soewon-gu, \\ Cheongju 28644, Korea \\ Tel $+82-43-269-6157$ \\ Fax $+82-43-265-6157$ \\ E-mail yschoi@chungbuk.ac.kr
}

Background and Objectives The incidence of recurrence after surgery of congenital cholesteatoma is increasing due to the widespread use of otoendoscopy as well as an increased awareness of these lesions among primary care physicians. There is no general consensus on the risk factors affecting recurrence. In this study, analyzing clinical characteristics of recurred cases from a tertiary hospital, we investigated risk factors for the recurrence of congenital cholesteatoma after surgery.

Subjects and Method From 1999 to 2016, data were collected from retrospective chart reviews of patients who have undergone surgeries for congenital cholesteatoma at Hospital. We analyzed data about clinical characteristics and recurrence according to the age at diagnosis, location, stage and type of disease, pneumatization of mastoid, ossicular erosion, and surgical techniques.

Results Sixty-eight patients underwent surgery for congenital cholesteatoma. The average age at operation was 4.8 years. Recurrence was detected in 7 cases of the 68 patients, with the recurrence rate of $10.3 \%$. Sex, age, cholesteatoma type, location, stage, mastoid pneumatization, and operation method did not show significant differences between the recurred group and the non-recurred group in the univariated analysis.

Conclusion The recurrence rate of congenital cholesteatoma after primary operation was $10.3 \%$. In this study, there was no statistically significant risk factor for postoperative recurrence of congenital cholesteatoma. Korean J Otorhinolaryngol-Head Neck Surg 2017;60(11):554-8

Key Words Cholesteatoma - Congenital - Recurrence $\cdot$ Risk factor.

\section{서 론}

선천성 진주종은 소아에서 호발하며, 정상 고막 내측에 위 치하는 회백색의 상피 종물이다. 그 빈도는 전체 진주종의 2 5\%를 차지하고, 소아의 진주종 중 4 24\%를 차지하는 드 물지 않은 질환이다. ${ }^{1,2)}$ 근본적 치료는 외과적 절제술이 원칙

This is an Open Access article distributed under the terms of the Creative Commons Attribution Non-Commercial License (http://creativecommons.org/licenses/by-nc/4.0) which permits unrestricted non-commercial use, distribution, and reproduction in any medium, provided the original work is properly cited.
이며 주로 고실 개방술을 통해 제거하게 된다. 재발을 줄이기 위해 수술 시 완전 제거를 목표로 하고 있지만, 30 52\% 정도 에서 재발이 보고되고 있다. ${ }^{3-6)}$ 게다가 최근 내시경 진찰이 보 편화되면서 질환의 빈도가 점차 증가함과 더불어, 재발 또한 점차 증가하고 있다.,8) 이에 수술 후 재발을 줄이기 위한 임상 적 연구와 시도가 활발한 상태이다.

본 연구에서는 본원에서 경험한 선천성 진주종의 치료 경험 을 보고하고, 재발한 환자군과 재발하지 않은 환자군을 대상으 로 재발에 영향을 끼치는 인자에 대해 비교 분석하고자 하였다. 


\section{대상 및 방법}

1999년 1월부터 2016년 3월까지 본원에 내원하여 Levenson 등)이 제시한 기준에 따라 선천성 진주종으로 진단받고 수 술적 치료를 시행받은 68 명의 환자들을 대상으로 하였으며, 의무기록 및 영상 자료를 통해 후향적으로 분석을 시행하였다. 본 연구는 본원의 임상시험윤리위원회(Institutional Review Board, IRB No. 2017-04-004) 심의를 승인받았다. 성별 및 연령, 진주종의 위치, $\mathrm{McGill}$ 등이이 제시한 기준을 근거로 개 방형과 폐쇄형의 진주종 유형, Potsic 등'ㅣㅇㅣ 제시한 기준에 따 른 병기(Table 1, Fig. 1), 수술 방법, 그리고 재발 여부 등에 대 해 조사하였다.

선천성 진주종에 대한 정의는 Levenson 등'이 제시한 기 준을 근거로 하여 1) 정상적인 고막의 내측에 존재하는 백색
종물로, 2) 고막의 이완부와 긴장부가 정상 소견을 보이며, 3) 이루와 천공의 과거력이 없으며, 4) 이과적 수술의 과거력이 없 는 환자를 대상으로 하였다. 외이도 폐쇄증, 고막내진주종은 제외하였고, 삼출성 중이염의 병력은 배제하지 않았다. ${ }^{9)}$ 진주 종의 위치는 추골병을 기준으로 전방부 병변과 후방부 병변으 로 나누었다.

총 68예의 수술은 모두 전신마취하에서 두 명의 선임 술자 에 의해 시행되었고, 수술적 접근법은 내시경 고막 소견과 측두골 전산화단층촬영 결과로 병변의 위치와 범위를 참고 하여 선택되었다. 선천성 진주종의 재발 여부를 확인하기 위해 정기적인 외래 경과 관찰 시 이내시경검사를 시행하였고, 내시 경검사상 의심이 될 시에는 측두골 전산화단층촬영을 시행하 여 진주종의 재발 유무를 확인하였다.

통계학적 분석은 SPSS version 12.0(SPSS Inc., Chicago,

Table 1. Staging system for congenital cholesteatoma

\begin{tabular}{cl}
\hline Stage & \multicolumn{1}{c}{ Description } \\
\hline 1 & Single quadrant: no ossicular involvement or mastoid extension \\
2 & Multiple quadrant: no ossicular involvement or mastoid extension \\
3 & Ossicular involvement: includes erosion of ossicles and surgical removal for eradication of disease; \\
4 & no mastoid involvement \\
\hline
\end{tabular}
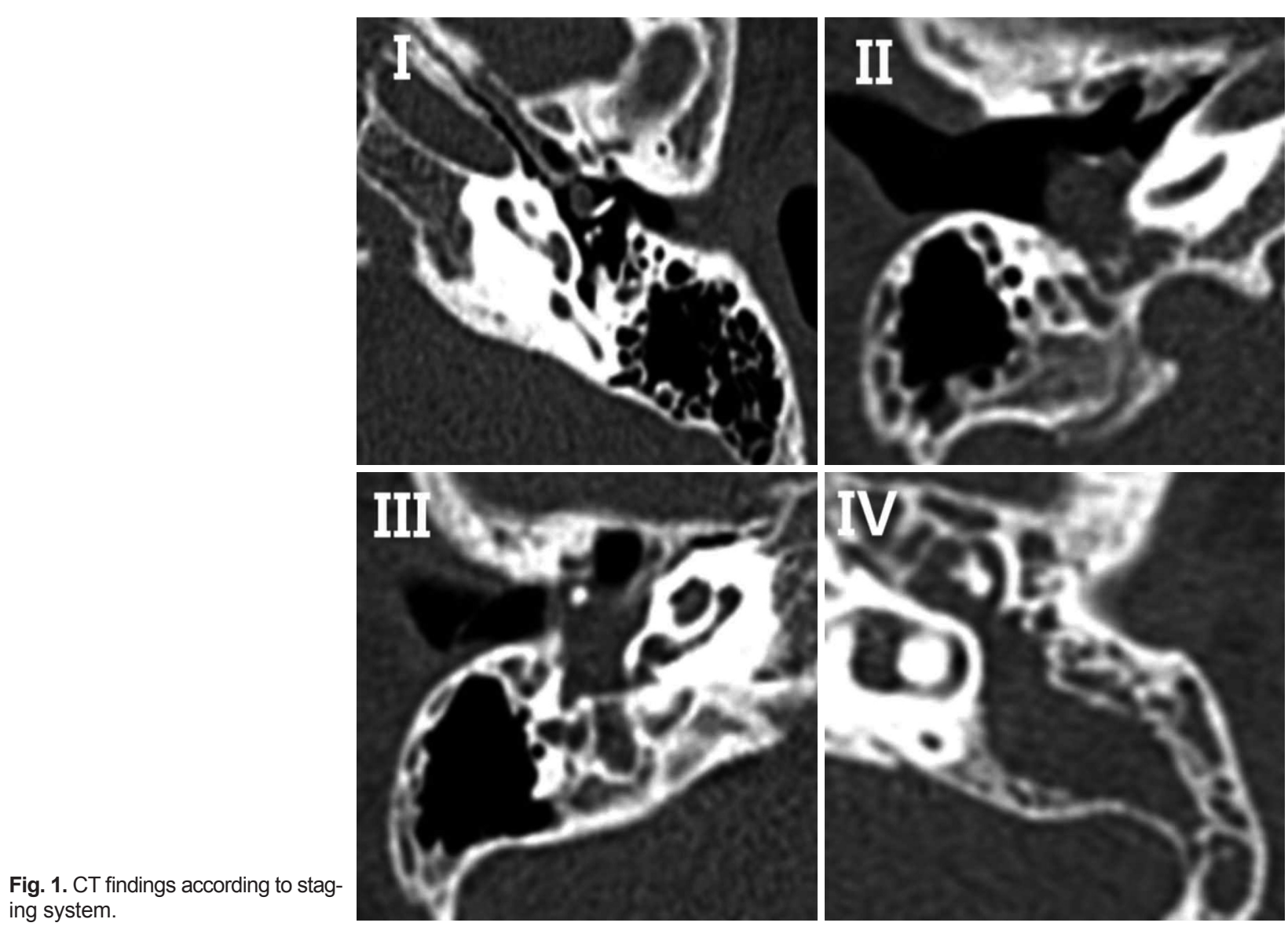
IL, USA)을 이용하여 시행하였으며 재발군과 재발하지 않은 두 군 간에 성별 및 연령, 측두골의 함기화 정도, 진주종의 유 형, 병기, 위치, 그리고 수술 방법 등에 따라 차이가 있는지를 각 각 비교하였다. 비교를 위해 Mann-Whitney's U test, Fisher's exact test를 사용하였으며, $p$-value가 0.05 이하일 때 통계 학적으로 유의하다고 정의하였다.

\section{결 과}

\section{임상적 특징}

총 68명의 선천성 진주종 환자의 진단 당시 평균 연령은 4.8세 (1 19세)였으며, 남자 53예, 여자 15예였다. 모두 일측 병변이 었으며 우측 33예, 좌측 35예였다.

측두골의 함기화 정도는 함기형 59예, 경화형 2예, 기타 7예 였다. 선천성 진주종을 위치와 유형 및 병기에 따라 분류하 였을 때 추골병 전방에 위치한 경우가 40예, 후방에 위치한 경 우가 28예였다. 폐쇄형 36예, 개방형 32예의 비율을 보였고, 병기별로는 병기 I 39예(57.3\%), 병기 II 12예(17.6\%), 병기 III 11예(16.2\%), 그리고 병기 IV가 6예로 8.9\%였다(Table 2).

수술적 접근은 개방성 유돌절제술은 시행되지 않았으며, 고 실개방술이 57예, 폐쇄형 유돌절제술이 11예 시행되었다. 수술 중 이소골 파괴가 발견된 경우는 22예, 이소골이 파괴되지 않 았던 경우는 46예였다.

\section{재발 및 재발 관련 인자}

선천성 진주종으로 수술받은 68명의 환자 중에 7명에서 재 발 소견이 관찰되었으며, 이는 $10.3 \%$ 에 해당하였다.

수술 당시 연령이 7세 이하에서 6예, 7세 초과에서 1예 재발 하였으며, 연령에 따른 유의한 차이 또한 보이지 않았다 $(p=$ 0.544). 남자 53명에서 6명(11.3\%)에서 여자 15명 중 1명(6.6\%) 에서 재발하였으며, 성별에 따른 유의한 차이 또한 보이지 않 았다 $(p=0.840)$. 측두골의 함기화 정도에서 함기형에서 $5.1 \%$, 경화형에서 $100 \%$ 재발하였다. 진주종의 위치에 따라서 재발 률에 유의한 차이는 없었으며 $(p=0.664)$, 진주종의 유형을 개 방형과 폐쇄형으로 나누어 비교 시 폐쇄형에서 $5.4 \%$, 개방형
에서 $16.1 \%$ 재발하였다 $(p=0.236)$. 병기별로는 병기 I의 경우 $2.5 \%$, 병기 II $14.2 \%$, III와 IV의 경우에도 $15.4 \%$ 와 $25 \%$ 로 병 기가 증가함에 따라 재발률이 높아지는 소견을 보였으나 통 계적으로는 유의한 차이를 보이지 않았다 $(p=0.068)$. 수술 소 견상 이소골 파괴 유무에 따라 이소골의 파괴가 있었던 경우 $18.2 \%$ 에서, 파괴가 없었던 경우 $6.5 \%$ 에서 재발 소견을 보였 다 $(p=0.202)$. 수술 접근 방법에 따라서 재발률에 차이는 없었 다 $(p=0.078)$ (Table 3$)$.

\section{고 찰}

선천성 진주종은 소아에서 주로 발생하며, 병의 진행에 따 라 고막 천공, 이소골 파괴 등 중이의 구조물을 파괴하여 청 력저하가 발생하게 된다. 초기 선천성 진주종의 경우에는 대 부분 증상이 없기 때문에 진단이 늦어지는 경우가 많으며, 청 력 감소, 안면 마비, 전정기능 저하 등의 증상이 나타난 후 진 단이 되는 경우 회복이 어려운 경우가 많기 때문에 조기에 진단과 적절한 치료가 필수적이다. 선천성 진주종의 치료 원 칙은 완전한 외과적 제거이며, 질환의 진행 정도에 따라 수 술 방법을 결정하게 된다.

수술 후 재발은 보통 진주종의 불완전한 제거 후 잔존하 는 진주종 상피에서 다시 재발하는 것으로 생각된다. 이러한 빈도는 이전의 연구들에서 29.5 52.0\%로 비교적 높게 보고 되었으나, ${ }^{3,911,12)}$ 최근 연구에서는 9.9 18.9\% 정도로 낮아졌 다. ${ }^{13,14)}$ 본 연구에서는 $10.3 \%$ 에서 재발을 보여 최근의 연구들 에 비해 낮은 결과를 보였다. 이는 고해상도 전산화단층촬영 과 내시경 발달에 힘입어 점점 빨라지는 조기 진단으로 인해 재발률이 낮아지는 것으로 생각된다. 본 연구에서 진단 당시 평균 연령은 4.8세로 기존 보고된 13.0세, ${ }^{14)} 7.9$ 세 ${ }^{8}$ 보다 낮았 으며, 이러한 점이 낮은 재발률에 영향이 있었을 것으로 생각 된다.

Kim 등 ${ }^{15)}$ 은 선천성 진주종의 연령에 따른 유형과 병기를 조사하였고, 3세 이상에서 병기 III 이상의 진주종이 증가하고 7세 이상에서는 폐쇄형 병변보다 개방형 병변이 유의하게 높 다고 보고한 바 있다. 본 연구에서 역시 연령이 증가할수록 병

Table 2. Stage of cholesteatoma according to the type and the location

\begin{tabular}{|c|c|c|c|c|c|}
\hline \multirow{2}{*}{ Stage } & \multicolumn{2}{|c|}{ Cholesteatoma type } & \multicolumn{2}{|c|}{ Cholesteatoma location } & \multirow{2}{*}{ Total } \\
\hline & Closed type & Open type & Anterior & Posterior & \\
\hline Stage I & 30 & 9 & 29 & 10 & 39 \\
\hline Stage ॥ & 4 & 8 & 8 & 4 & 12 \\
\hline Stage III & 0 & 11 & 1 & 10 & 11 \\
\hline Stage IV & 0 & 6 & 1 & 5 & 6 \\
\hline Total & 34 & 34 & 39 & 29 & 68 \\
\hline
\end{tabular}


Congenital Cholesteatoma I Oh YS, et al.

Table 3. Comparisons of various prognostic factors among the non-recurred group and the recurred group after surgery

\begin{tabular}{|c|c|c|c|c|}
\hline & Non-recurred group (\%) & Recurred group (\%) & Total & $\mathrm{p}$-value \\
\hline Sex & & & & 0.840 \\
\hline Male & $47(88.7)$ & $6(11.3)$ & 53 & \\
\hline Female & $14(93.3)$ & $1(6.7)$ & 15 & \\
\hline Age & & & & 0.544 \\
\hline Below 7 years & $55(90.2)$ & $6(9.8)$ & 61 & \\
\hline Above 7 years & $6(85.7)$ & $1(14.3)$ & 7 & \\
\hline Mastoid pneumatization & & & & Not applicable \\
\hline Pneumatic & $56(94.9)$ & $3(5.1)$ & 59 & \\
\hline Sclerotic & $0(0.0)$ & $2(100.0)$ & 2 & \\
\hline Others & $5(71.4)$ & $2(28.6)$ & 7 & \\
\hline Cholesteatoma location & & & & 0.664 \\
\hline Anterior & $37(92.5)$ & $3(7.5)$ & 40 & \\
\hline Posterior & $24(85.7)$ & $4(14.3)$ & 28 & \\
\hline Cholesteatoma type & & & & 0.236 \\
\hline Closed type & $35(94.6)$ & $2(5.4)$ & 37 & \\
\hline Open type & $26(83.9)$ & $5(16.1)$ & 31 & \\
\hline Cholesteatoma stage & & & & 0.068 \\
\hline I & $38(97.4)$ & $1(2.6)$ & 39 & \\
\hline ॥ & $10(83.3)$ & $2(16.7)$ & 12 & \\
\hline III & $9(81.8)$ & $2(18.2)$ & 11 & \\
\hline IV & $4(66.7)$ & $2(33.3)$ & 6 & \\
\hline Ossicle erosion & & & & 0.202 \\
\hline Yes & $18(81.8)$ & $4(18.2)$ & 22 & \\
\hline Intact & $43(93.5)$ & $3(6.5)$ & 46 & \\
\hline Surgical methods & & & & 0.078 \\
\hline Exploratory tympanotomy & $53(93.0)$ & $4(7.0)$ & 57 & \\
\hline Canal wall up mastoidectomy & $8(72.7)$ & $3(27.3)$ & 11 & \\
\hline Canal wall down mastoidectomy & $0(0.0)$ & $0(0.0)$ & 0 & \\
\hline Total & $61(89.7)$ & $7(10.3)$ & 68 & \\
\hline
\end{tabular}

기가 증가하였으며, 병기가 높아질수록 개방형 병변이 증가하 고 폐쇄형 병변이 적어지는 경향을 보였다. 이러한 이유로 연 령이 어릴수록 재발률이 낮으며, 이에 조기 진단이 중요하다는 보고가 있었으나, ${ }^{16)}$ 본 연구에서는 평균 연령 7세를 기준으로 하였을 때 연령에 따른 재발률에 차이가 있지는 않았다.

측두골함기화 정도에 따른 재발률을 보면, 경화형의 경우 이관기능이 나쁜 것을 반증하며, 진주종의 중이 침습이 깊어 병 변 제거가 불완전할 수 있기에 재발이 높을 것으로 생각된다. 본 연구에서 역시 경화형의 경우 59명 중 3명(5.1\%)에서, 함기 형의 경우 2명 중 2명 모두(100\%)에서 재발하였으나, 통계적 인 검증은 불가하였다.

Iino 등 ${ }^{17)}$ 은 잔여 진주종의 위험인자로 진주종이 후상방 에 위치한 경우를 제시하였고 이는 진주종이 후상방에 위치 한 경우 침골의 장각 및 등골의 상완각 손상, 그리고 진주종 의 고실동 침범이 흔하게 나타나기 때문이라고 설명하였다. 본 연구에서도 진주종이 후방부에 위치한 경우 재발률이 높
았으나 통계학적으로 유의한 차이는 없었다.

$\mathrm{McGill}$ 등인 슨 선천성 진주종을 조직학적으로 폐쇄형과 개 방형인 두 유형으로 분류하였는데, 폐쇄형은 전상방에서 많 이 발생하고 수술 시 제거하기 용이하게 피막으로 잘 덮여 있 는 반면, 개방형은 진주종이 중이 점막과 맞닿아 있어 잔여 진주종의 가능성이 높다고 하였다. 본 연구에서도 개방형의 경우 재발률이 더 높았으나, 통계적으로 유의한 차이를 보이 지는 않았다.

이소골 파괴에 대해서는 이소골 손상이 진행된 병변을 의 미하기에 재발률이 높다는 의견이 대부분이나, 수술 중 이소 골 파괴가 있어 이소골을 제거하게 되면 보다 넓은 수술 시 야를 확보할 수 있기에 병변의 완전 제거에 유리하다는 의견 도 있다. 본 연구에서는 이소골 손상이 있었던 경우에서 재발 률이 높았으나 통계학적으로는 유의한 차이가 없었다.

수술 방법에 따른 재발의 위험 인자로 Shirazi 등ㄴ)은 폐쇄 형 유양돌기 절제술을 시행한 경우 이차관찰 수술이 필요하다 
고 하였으며, 본 연구에서도 폐쇄형 유양돌기 절제술 시 재발 률이 높았으나 통계학적인 차이는 없었다. 소아 선천성 진주종 에서 개방형 유양돌기 삭개술은 가능하면 피해 공동 문제를 최소화해야 하며, ${ }^{18,19)}$ 본 연구에서는 개방형 유양돌기 삭개 술을 시행한 경우는 없었다. 더 나아가 최근에는 최소 침습수 술에 대한 관심이 증가하면서, 유양돌기 절제술 등을 통해 추 가적인 접근 경로를 만들어 병변의 완전한 제거를 꾀하는 것 이 아니라, 추가적 절제 없이 좁은 공간의 병변을 확인하는 데 용이한 내시경을 사용한 수술까지도 시행되고 있다. ${ }^{20)}$ 이러한 최소 침습수술 방법이 재발에 미치는 영향에 대해서는 추가적 인 연구가 필요하리라 생각된다.

\section{REFERENCES}

1) Paparella MM, Rybak L. Congenital cholesteatoma. Otolaryngol Clin North Am 1978;11(1):113-20.

2) McDonald TJ, Cody DT, Ryan RE Jr. Congenital cholesteatoma of the ear. Ann Otol Rhinol Laryngol 1984;93(6 Pt 1):637-40.

3) Friedberg J. Congenital cholesteatoma. Laryngoscope 1994;104(3 Pt 2):1-24.

4) Shirazi MA, Muzaffar K, Leonetti JP, Marzo S. Surgical treatment of pediatric cholesteatomas. Laryngoscope 2006;116(9):1603-7.

5) Nelson M, Roger G, Koltai PJ, Garabedian EN, Triglia JM, Roman $\mathrm{S}$, et al. Congenital cholesteatoma: classification, management, and outcome. Arch Otolaryngol Head Neck Surg 2002;128(7):810-4.

6) Ueda $H$, Nakashima T, Nakata S. Surgical strategy for cholesteatoma in children. Auris Nasus Larynx 2001;28(2):125-9.

7) Potsic WP, Korman SB, Samadi DS, Wetmore RF. Congenital cholesteatoma: 20 years' experience at The Children's Hospital of Philadelphia. Otolaryngol Head Neck Surg 2002;126(4):409-14.

8) Kim HJ. Congenital cholesteatoma: diagnosis and management. Korean J Otorhinolaryngol-Head Neck Surg 2013;56(8):482-9.
9) Levenson MJ, Michaels L, Parisier SC. Congenital cholesteatomas of the middle ear in children: origin and management. Otolaryngol Clin North Am 1989;22(5):941-54

10) McGill TJ, Merchant S, Healy GB, Friedman EM. Congenital cholesteatoma of the middle ear in children: a clinical and histopathological report. Laryngoscope 1991;101(6 Pt 1):606-13.

11) Potsic WP, Samadi DS, Marsh RR, Wetmore RF. A staging system for congenital cholesteatoma. Arch Otolaryngol Head Neck Surg 2002; 128(9):1009-12.

12) Levenson MJ, Parisier SC, Chute P, Wenig S, Juarbe C. A review of twenty congenital cholesteatomas of the middle ear in children. Otolaryngol Head Neck Surg 1986;94(5):560-7.

13) Choi HG, Park KH, Park SN, Jun BC, Lee DH, Park YS, et al. Clinical experience of 71 cases of congenital middle ear cholesteatoma. Acta Otolaryngol 2010;130(1):62-7.

14) Kim DK, Kim HM, Suh MW, Lee JH, Oh SH, Kim CS, et al. Analysis of risk factors for the occurrence of residual cholesteatoma after congenital cholesteatoma surgery. Korean J OtorhinolaryngolHead Neck Surg 2008;51(2):120-4.

15) Kim YH, Yoo JC, Lee JH, Oh SH, Chang SO, Koo JW, et al. Stage progression of congenital cholesteatoma in children. Eur Arch Otorhinolaryngol 2012;269(3):833-7.

16) Lazard DS, Roger G, Denoyelle F, Chauvin P, Garabédian EN. Congenital cholesteatoma: risk factors for residual disease and retraction pockets--a report on 117 cases. Laryngoscope 2007;117(4): 634-7.

17) Iino Y, Imamura Y, Kojima C, Takegoshi S, Suzuki JI. Risk factors for recurrent and residual cholesteatoma in children determined by second stage operation. Int J Pediatr Otorhinolaryngol 1998;46(1-2):57-65.

18) DeRowe A, Stein G, Fishman G, Berco E, Avraham S, Landsberg R, et al. Long-term outcome of atticotomy for cholesteatoma in children. Otol Neurotol 2005;26(3):472-5.

19) De la Cruz A, Fayad JN. Detection and management of childhood cholesteatoma. Pediatr Ann 1999;28(6):370-3.

20) Yang CJ, Kim SH, Chung JW. Usefulness of Endoscopic Removal of Congenital Cholesteatoma in Children. Korean J OtorhinolaryngolHead Neck Surg 2016;59(3):194-201. 